\title{
Shell Mold Cracking and Its Prediction during Casting of AC4C Aluminum Alloy*
}

\author{
Shuxin Dong ${ }^{1}$, Yasushi Iwata ${ }^{1}$, Hiroshi Hohjo ${ }^{1}$, Hiroaki Iwahori ${ }^{1}$, \\ Takashi Yamashita ${ }^{2}$ and Haruyoshi Hirano ${ }^{2}$ \\ ${ }^{1}$ Materials Fundamental Research Division, Toyota Central R\&D Labs., Inc., Aichi-gun, Aichi 480-1192, Japan \\ ${ }^{2}$ Engine Division, Toyota Industries Corporation, Hekinan 447-8507, Japan
}

\begin{abstract}
The mechanism of shell mold cracking and its prediction during casting of aluminum alloy were elucidated. A cylindrical shell mold made of silica sand fractures easily when filled with aluminum alloy melt. The cracking mechanism can be considered as follows. The immediate inner surface of a shell mold undergoes a sudden temperature rise from heating by the melt and attempts to expand. This thermal expansion is restrained by the other part of the mold that is still low in temperature. Consequently, compressive stress in the area near the inner surface and tensile stress in the area near the outer surface develop respectively, causing the shell mold to fracture when the tensile stress exceeds the tensile strength of the shell mold. With some part of a cylindrical shell mold cut to a thinner thickness, a higher tensile stress acts on the outer surface of the thinner part and a crack is formed in a shorter time after the mold has been filled with aluminum alloy melt. The criterion for shell mold cracking can be described by the relation of fracture stress and effective volume based on the Weibull's statistical method, which is utilized for evaluating the strength of brittle materials. The relation of fracture stress and effective volume enabling us to predict the shell mold cracking was obtained from the statistical properties of the tensile strength of the shell mold material. [doi:10.2320/matertrans.F-M2010815]
\end{abstract}

(Received March 8, 2010; Accepted June 2, 2010; Published July 14, 2010)

Keywords: shell mold, crack, fracture stress, effective volume, prediction, veining, casting, aluminum, alloy

\section{Introduction}

One of the fundamental advantages of casting is being able to manufacture components of intricate cavities such as cylinder heads of automotives in a single piece without assembly. The mold used for this process is comprised of a main mold and some core molds which are generally made of shell molds or organic self-hardening sand especially for complex shape cavities. However, if a crack occurs even at one place of the core molds during casting, the casting of the cylinder head may become a defective product due to burrs or fins formed due to the solidification of melt penetrating into the crack. These defects, which are referred to as veining defects in foundry, are difficult to be detected and removed thus it is essential to know the correct casting conditions that can avoid such defects completely before mass production.

The veining defect is a kind of defects generally encountered in sand mold castings together with metal penetration, pinholes, and blowholes. It is also considered prone to occur in sand molds using organic binders. J. Campbell ${ }^{1)}$ assumes that veining defects arise from the thermal expansion of sand molds due to heating by melt, but what extent of the thermal expansion can lead to sand mold cracking and when the crack appears during casting are left to be clarified. Makiguchi ${ }^{2}$ suggests that veining defects occur when the type of binder, grain size, filling state of sand, pouring temperature of melt are not appropriate, and are also influenced by shapes and dimensions of castings. Oota ${ }^{3)}$ reports that the thermal expansion coefficient of sand has little to do with veining defects. There are also reports concerning measures against veining defects. One is adding some substances which react with sand to form some glassy substances. ${ }^{4)}$ The other is mixing boric acid or other

*This Paper was Originally Published in Japanese in J. JFS 82 (2010) 79 85 . substances with sand to improve the deformability of the surface layer of sand molds at elevated temperatures, ${ }^{5)}$ or adding $\mathrm{Fe}_{2} \mathrm{O}_{3}$ to sand. ${ }^{6,7)}$ Coating additives which can seal the cracks on the surfaces of sand molds by softening at elevated temperatures are also commercially available. The above researches for preventing veining defects were mainly conducted for cast iron or cast steel. It is still challenging to eliminate veining defects completely.

On the other hand, in last decades the simulation technologies for foundry engineering have progressed remarkably. Prediction of casting quality and die design are being conducted flourishingly based on numerical analyses of mold filling and solidification in foundries here and there. ${ }^{8,9)}$ Nevertheless, the simulation techniques for sand molds or cores are still under development such as the prediction of veining defects because the mechanical model of sand molds and the cracking mechanism of mold surfaces are not understood adequately.

In this study, the thermo-mechanical behavior of shell molds at being heat by melt during casting was investigated as related to mold surface cracking. The criterion for cracking was proposed and predictions based upon the criterion were carried out in actual foundry production of cylinder head castings.

\section{Experimental Method}

\subsection{Casting experiments}

The cup-shaped experimental mold shown in Fig. 1, was made of shell mold with a inside diameter of $60 \mathrm{~mm}$, a height of $120 \mathrm{~mm}$ and a thickness of $10 \mathrm{~mm}$. The shell mold was formed in a steel mold using resin coated sand (RCS) which was prepared by mixing JIS100 silica sand $\left(99.8 \% \mathrm{SiO}_{2}\right)$ with 1.5 mass $\%$ phenolic resin and was cured at $300^{\circ} \mathrm{C}$. The cracking phenomenon was examined when pouring JISAC4C aluminum alloy (Hereafter, called AC4C alloy) melt 


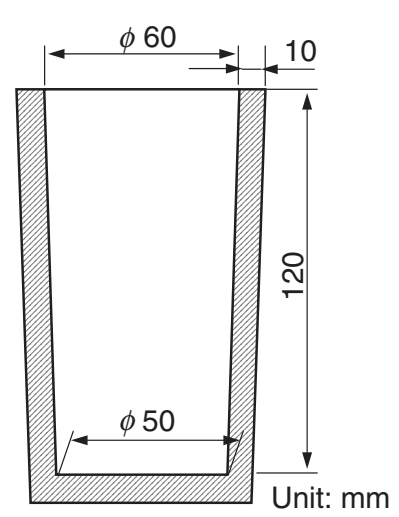

Fig. 1 Cylindrical experimental shell mold.

at $700^{\circ} \mathrm{C}$ into the cup-shaped experimental mold where the filling time was about $3 \mathrm{~s}$. The effect of mold wall thickness on cracking was also investigated by grinding a part of the mold wall to various thicknesses vertically.

To investigate the effect of pouring methods on cracking, the following pouring experiments were also carried out.

(1) Pouring to the inner side or outer side of the mold only, i.e. only the inner side or outer side contacts melt.

(2) Pouring to the inner side and outer side of the mold simultaneously, i.e. the inner side and outer side contact melt at the same time.

(3) Pouring to the inner side and outer side of the mold with a time lag, i.e. the inner side contacts melt prior to the outer side or the reversal.

The mold used for these experiments was a $40 \mathrm{~mm}$ high cylinder-shaped mold cut out from the upper part of the cup-shaped mold shown in Fig. 1. The filling time was $1 \mathrm{~s}$ for both the inner side and outer side of the mold.

The strains generated in the cup-shaped mold during pouring were measured by installing strain gages on the outer surface of the mold in circumferential direction at a height of $60 \mathrm{~mm}$ from the bottom. To avoid the dissipation of the adhesive of the strain gage into the grain interstitial of the mold, a type of high viscosity adhesive was adopted. A kind of high temperature strain gage, ZFLA-3 (by Tokyo Sokki Kenkyujo co., Ltd.) was used in the above measurements. The occurrence and propagation process of the crack was recorded by a high speed camera with a recording speed of $1 \times 10^{5} \mathrm{fps}$.

\subsection{Thermal stress analyses for the sand mold}

The thermo-mechanical coupled analyses of the mold were carried out with the commercial structure analysis code MSC. MARC in two-dimensions or three-dimensions depending on the purposes. To examine the relation between stress and mold cracking during pouring, a two-dimensional thermomechanical analysis was conducted with a ring-shaped model assumed as the horizontal cross section of the mold. It is necessary to calculate the temperature variation in the mold with a high accuracy in order to acquire the correct stress distribution. Besides measuring the thermal properties of the mold, the heat transfer coefficient at the interface between melt and mold surface was determined by the following method. A cup-shaped mold was made for temperature measurement with three $\Phi 0.1 \mathrm{~mm}$ chromel-alumel thermal couples embedded at three positions in the thickness direction of the mold wall with a interval of approximately $2.5 \mathrm{~mm}$ and at a height of $60 \mathrm{~mm}$ from the bottom. The correct positions of the thermocouples were confirmed by the $\mathrm{X}$-rays transmission photograph before pouring and recorded together with the temperature measuring results of the thermal couples during pouring. In the present study, the melt-mold interface heat transfer coefficient at the first $30 \mathrm{~s}$ was considered of significance because the cracks of molds all occurred within $30 \mathrm{~s}$ after melt pouring. The heat transfer coefficient was calculated as $0.05 \mathrm{cal} \cdot \mathrm{cm}^{-2} \cdot{ }^{\circ} \mathrm{C}^{-1} \cdot \mathrm{s}^{-1}$ by the inverse method in which the heat transfer coefficient giving the nearest calculated temperatures to the measured results is chosen as the correct heat transfer coefficient. In the above thermal calculations obtaining the heat transfer coefficient, a two dimensional analysis was adopted. The time when the melt surface in the mold arriving at the position of the embedded thermal couples during pouring was taken as the starting time of the analysis. The heat transfer coefficient of the mold-air interface was accepted as $0.0008 \mathrm{cal} \cdot \mathrm{cm}^{-2}$. ${ }^{\circ} \mathrm{C}^{-1} \cdot \mathrm{s}^{-1}$.

A three dimensional analysis taking into account the filling process of melt was also carried out to calculate the temperature and stress distributions in the cup-shaped mold. To describe the gradual heating process of the mold correctly during the $3 \mathrm{~s}$ of melt filling in the analyses, the $120 \mathrm{~mm}$ height of the mold cavity was divided into 24 sections equally. Each ring-shaped section has a height of $5 \mathrm{~mm}$ and a heat transfer boundary condition with a heat transfer coefficient of $0.05 \mathrm{cal} \cdot \mathrm{cm}^{-2} \cdot{ }^{\circ} \mathrm{C}^{-1} \cdot \mathrm{s}^{-1}$ and a environmental temperature of $700^{\circ} \mathrm{C}$ was applied to the inner surface of the ring-shaped mold from the bottom to the top consecutively with a time lag of $0.125 \mathrm{~s}$. The object of the above thermomechanical analysis was taken as the mold only and the radiation heat transfer of the melt surface in the mold was ignored.

The analyses for the $40 \mathrm{~mm}$ high cylinder-shaped mold were done in a two-dimensional model consisting of the mold and melt but ignoring the filling time of $1 \mathrm{~s}$.

The thermal and mechanical properties of the mold are shown in Table 1. The mechanical properties were acquired by tensile and compressive tests using dumbbell-shaped planar specimens $(5.5 \mathrm{~mm}$ in thickness, $25 \mathrm{~mm}$ in width, $75 \mathrm{~mm}$ in gage length, and a transition part radius of $30 \mathrm{~mm}$ ) and column specimens ( $20 \mathrm{~mm}$ in diameter, $40 \mathrm{~mm}$ in length)

Table 1 Thermal and mechanical properties of shell mold used for thermal and mechanical simulation.

\begin{tabular}{cc}
\hline Density $\left(\mathrm{kg} \cdot \mathrm{m}^{-3}\right)$ & $1.55 \times 10^{3}$ \\
\hline Thermal conductivity $\left(\mathrm{W} \cdot \mathrm{m}^{-1} \cdot{ }^{\circ} \mathrm{C}^{-1}\right)$ & 0.70 \\
\hline Specific heat $\left(\mathrm{J} \cdot \mathrm{kg}^{-1} \cdot{ }^{\circ} \mathrm{C}^{-1}\right)$ & $1.13 \times 10^{3}$ \\
\hline Linear thermal expansion coefficient $\left({ }^{\circ} \mathrm{C}^{-1}\right)$ & $1.16 \times 10^{-5}$ \\
\hline Tensile strength, $\sigma_{\mathrm{t}}(\mathrm{MPa})$ & 3.15 \\
\hline Compressive strength, $\sigma_{\mathrm{c}}(\mathrm{MPa})$ & 10.44 \\
\hline Modulus of elasticity, E $(\mathrm{GPa})$ & 3.72 \\
\hline Poisson's ratio $(-)$ & 0.20 \\
\hline
\end{tabular}




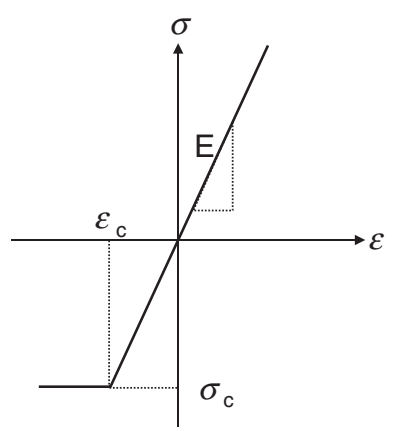

Fig. 2 Stress-strain model of shell mold used for mechanical simulation.

respectively. The specimens were made of the same sand and cured under the same conditions as the molds.

The mechanical properties of the mold at elevated temperatures were achieved through extrapolating the room temperature properties according to the temperature dependence of the three point bending strength which was measured by a series of bending tests from room temperature to $400^{\circ} \mathrm{C}$. The stress-strain curves at room temperature were measured by a video camera strain gage. The thermal conductivity, specific heat, density, and thermal expansion coefficient of the mold were measured by box probe method, vacuum bottle method, bulk density method, and JACT M-2 test method (Japan Association of Casting Technology) respectively.

The stress-strain behaviors of the mold were assumed as that illustrated in Fig. 2 in the thermo-mechanical analysis. The modulus and the compressive yield stress of the mold were taken as the measured values given in Table 1. As was described in section 3.5, the tensile strength of the mold varied considerably with the change of the effective volume, thus the stress-strain relation in the tensile area was assumed as that of a complete elastic material.

\section{Experimental Results and Discussions}

\subsection{Cracking and thermal stress of the experimental mold}

An instance of cracks occurred is shown in Fig. 3 when pouring AC4C alloy melt into the cup-shaped mold of Fig. 1. A crack began to propagate in the vertical direction of the mold wall companied by a sound and the melt in the mold flowed out through the crack at about 8 to $12 \mathrm{~s}$ from the start of pouring.

The calculated temperature and stress distributions in the mold wall along the thickness direction after contacting melt are illustrated in Fig. 4. The inner surface of the mold shows a rapid temperature rise on contacting melt, but the interior of the mold wall has slow temperature changes due to the low thermal conductivity of sand. Especially the outer surface of the mold which has a distance of $10 \mathrm{~mm}$ away from the inner surface hardly shows any temperature change in $10 \mathrm{~s}$ after pouring. The thermal stress distribution arising from the above temperature changes in the mold features a tensile stress at the outer side and a compressive stress at the opposite side, i.e., the inner side of the mold wall which contacting melt. The tensile stress at the outer side increases rapidly in a short time after pouring due to the thermal

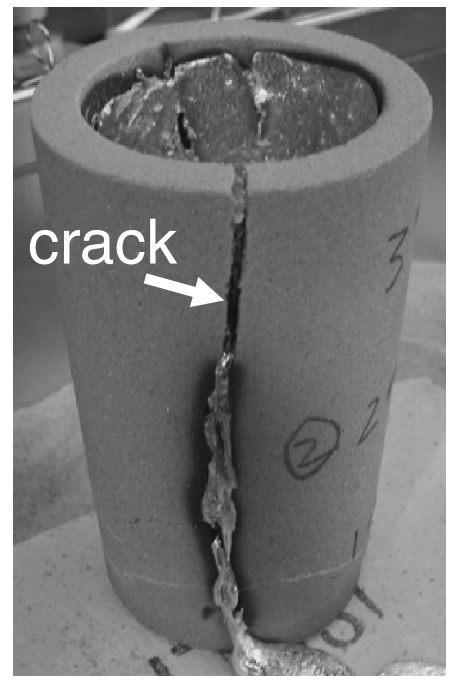

Fig. 3 Crack occurred in the cylindrical shell mold.

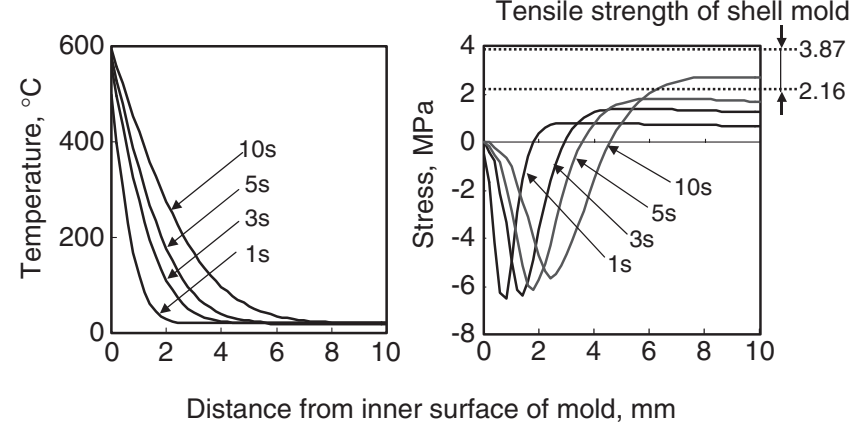

Fig. 4 Temperature and stress distributions along thickness direction in the cross section of cylindrical mold (two dimension analysis).

expansion of the silica sand of mold. That is to say, the mold having a linear thermal expansion coefficient of $1.16 \times$ $10^{-5 \circ} \mathrm{C}^{-1}$ will expand upon being heated. The inner side of the mold wall expands at the moment contacting melt, while the outer side of the mold wall does not expand because it is still at its original temperature due to the low thermal conductivity of the mold. Therefore, the thermal expansion of the heated inner side area is constrained by the outer side area the temperature of which stays unchanged resulting in a compressive stress and a tensile stress at the inner side and the outer side respectively. The area of heated inner side enlarges while the outer side area that stays at the original temperature decreases with time thus tensile stress at the outer side will increase because the tensile force has to match the compressive force in the cross section. It can be considered that a crack will occur when the tensile stress at the outer side exceeds the tensile strength of the mold. As shown in Fig. 4, the tensile stress had risen to the level of the tensile strength (a range of 2.16 to $3.87 \mathrm{MPa}$, averaged $3.15 \mathrm{MPa}$ ) in $8 \mathrm{~s}$ after the start of pouring. In experiments, the crack occurred at 8 to $12 \mathrm{~s}$ after the start of pouring. Considering that the above thermo-mechanical simulation was conducted with a two-dimensional model, the measuring errors of the mold properties, and the fluctuation of the sand filling during preparing the mold, the calculated cracking time should have included some estimated errors. Therefore, 


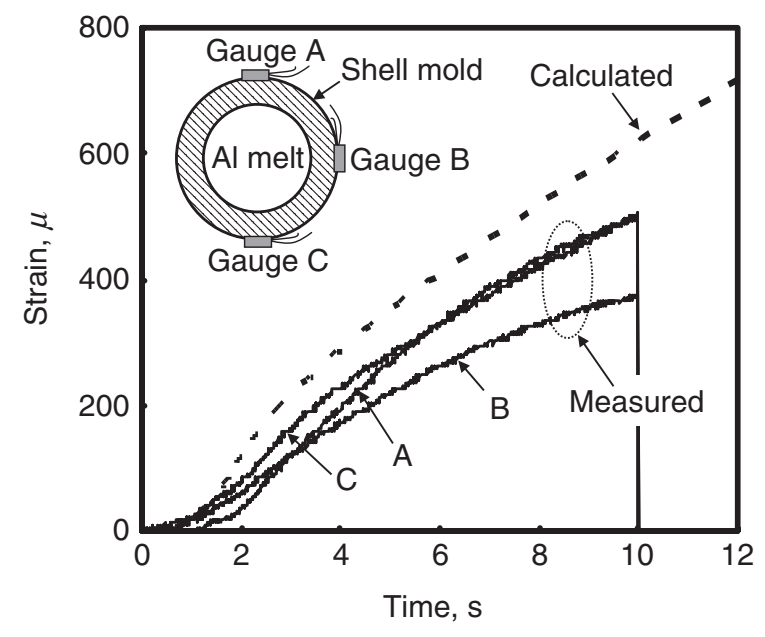

Fig. 5 Comparison of measured and calculated strains in the outer surface $60 \mathrm{~mm}$ high from the bottom of the cylindrical shell mold from the start of pouring (three dimension analysis).

it can be considered that the calculated cracking time agrees well to the measured value. An instance of the measured strain curves of the cup-shaped mold by installing strain gages on three positions of the outer surface circumferentially is shown in Fig. 5. When the inner surface was heated by melt, the tensile strains of the three positions at the outer surface of the mold began to increase and a crack occurred at a value of about $500 \mu$ in about $10 \mathrm{~s}$ after starting to pour. The strains of the three positions dropped simultaneously when a crack occurred. Comparing the strains in Fig. 5, it can be seen that the calculated and the measured strains show the same increasing tendency although the measured values are lower than the calculated values. The fluctuation around $100 \mu$ between the strains measured at the three positions may be explained by the effects of the unevenness of the gage adhesive and the filling of sand, etc.

\subsection{The effects of pouring methods on thermal stress and cracking}

It has been confirmed that the occurrence of the crack on the surface of the mold resulted from the thermal stress that exceeded the tensile strength of the mold. The relation between thermal stress and cracking was further investigated when changing pouring methods. In the first method, AC4C alloy melt was only poured to the inner or the outer side of the ring-shaped mold described in section 2.1. In the second method, AC4C alloy melt was poured to both the inner and the outer side of the ring-shaped mold at the same time. In the third method, AC4C alloy melt was first poured to the inner side or the outer side and then to the outer side or the inner side of the mold prior to cracking with a time lag of $6 \mathrm{~s}$. In each case of the first pouring method, pouring to the inner side or the outer side only, the crack occurred at the opposite side of pouring. For the second and the third method, no crack was observed. The temperature and stress distributions along the thickness direction of the mold wall calculated in a two dimensional model for the third filling method are illustrated in Fig. 6. Although there existed a tensile stress at the outer side of the mold wall at $5 \mathrm{~s}$ after melt filling into the inner side, the stress changed to a compressive stress at $6.5 \mathrm{~s}$ when
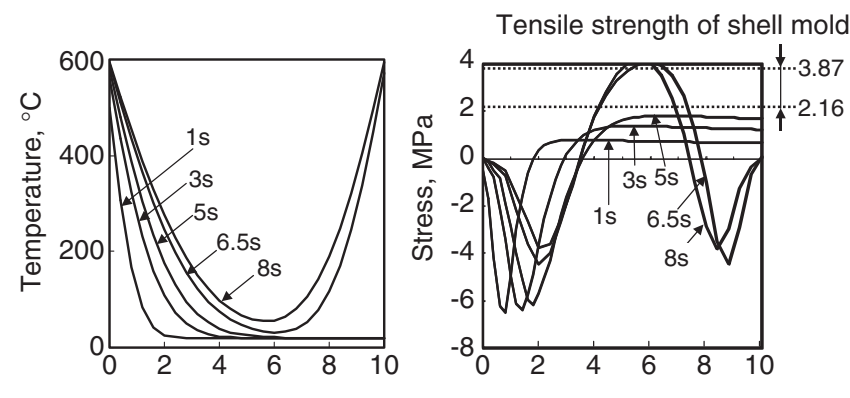

Distance from inner surface of mold, $\mathrm{mm}$

Fig. 6 Temperature and stress distributions along thickness direction in the cross section of the ring-shaped shell mold contacted melt with both inner and outer surfaces by a time lag of $6 \mathrm{~s}$ (two dimension analysis).

melt had been poured to the outer side of the ring-shaped mold and the compressive stress area continued to spread towards the center of the mold wall with time. The tensile stress of the central part in the thickness direction of the mold wall entered the tensile strength range at some time, but no crack was observed. In the filling process of the second pouring method in which $\mathrm{AC} 4 \mathrm{C}$ was poured to the inner and the outer sides of the mold at the same time, compressive stresses in both the inner and the outer surfaces and tensile stress in the central part in the thickness direction of the mold wall acted from the beginning of the pouring. The above experimental and simulation results suggest that cracks will occur if the tensile stress in the surfaces of the mold exceeds the tensile strength and the crack will not appear if the stresses in the surfaces are compressive even if the tensile stresses inside the mold wall are higher than the tensile strength of the mold.

\subsection{The origin of crack}

The stress distributions in cup-shaped mold with a part of the wall being ground to a thickness of $5 \mathrm{~mm}$ vertically are shown in Fig. 7. Figure 7(a) is fully filled and (b) is partly filled to the position $20 \mathrm{~mm}$ from the top edge of the mold. In Fig. 7(a), the highest stress acted on the lower area of the outer surface of the mold at $2.8 \mathrm{~s}$ from the beginning of filling and the point of the highest stress moved to the upper edge of the mold. The crack of the mold occurred in 6 to $7 \mathrm{~s}$ from the beginning of filling. The cracking time differs from that in Fig. 4 and the reasons will be discussed in the following section 3.4. The crack was observed to initiate at the upper edge and propagate toward the bottom of the mold with the help of a high speed camera. In Fig. 7(b), the highest stress acted on the lower area of the mold and the position of the highest stress hardly moved in the filling process. For this filling condition, the initial crack occurred at about $5 \mathrm{~s}$ from the beginning of filling and the crack was observed to propagate clearly toward the upper part of the mold. That is to say, for condition (a) there were two areas at the upper and lower parts of the mold showing comparatively high stresses and the stress of the upper part exceeded the tensile strength of the mold at the time the crack occurred. For condition (b), only the lower part of the mold had a peak of stress throughout the filling process and the stress at this area largely exceeded the tensile strength of the mold when the crack initiated at this point. 
(a)

Fully filled $(\mathrm{h}=120 \mathrm{~mm})$

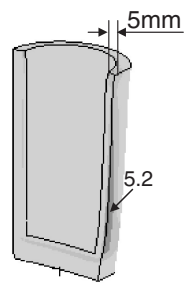

$t=2.8 s$

$\mathrm{t}=2.7 \mathrm{~s}$

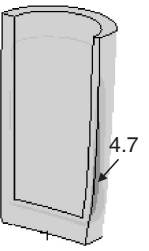

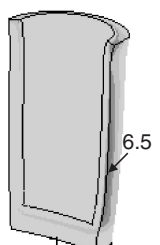

$\mathrm{t}=3.1 \mathrm{~s}$

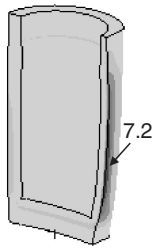

$\mathrm{t}=5.0 \mathrm{~s}$

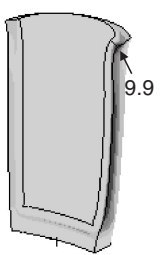

$t=5.7 \mathrm{~s}$

Maximum

Principal stress [MPa]

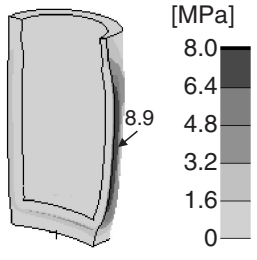

$\mathrm{t}=9.7 \mathrm{~s}$
Fig. 7 Stress distributions within the cylindrical shell molds fully and not fully filled with melt (a) fully filled with melt, (b) not fully filled with melt (100 times amplified deformation) (three dimension analysis).

\subsection{The shapes of molds and the cracking stresses}

For the mold that had a thinly ground part of $5 \mathrm{~mm}$ thickness as shown in Fig. 7(a), the crack occurred at 6 to $7 \mathrm{~s}$ from the beginning of melt filling. To investigate the effect of the thinly ground part on cracking, the thickness of the thinly ground parts were varied from $10 \mathrm{~mm}$ (not ground) to $3 \mathrm{~mm}$ and pouring experiments were carried out. In all the cases, the cracks occurred in the thinly ground parts and the times were about $8 \mathrm{~s}, 6.5 \mathrm{~s}$ and $4 \mathrm{~s}$ from the beginning of melt filling for the thinly ground part thicknesses of $10 \mathrm{~mm}, 8 \mathrm{~mm}$ and $3 \mathrm{~mm}$ respectively. The occurring time of crack became shorter with the decrease of the thickness of the thinly ground parts.

Strains generated in the surfaces of molds until cracking were measured and shown in Fig. 8 for different thicknesses of the thinly ground parts. For the not ground mold, the strains were about $500 \mu$ at all the three measured points when the crack occurred. However, with the decrease of thicknesses of the thinly ground parts, the strain in the thinly ground part became higher and the strains in the other parts became lower inversely at the time when crack occurred. Especially when the thicknesses of the thinly ground part were less than $5 \mathrm{~mm}$ the strain in the ground part rose rapidly with the decrease of the thickness of the thinly ground part and the strain for the thickness of $3 \mathrm{~mm}$ was as high as $3000 \mu$. The mean tensile strength of the mold was obtained as $3.15 \mathrm{MPa}$ by $N=10$ tensile tests as is shown in Table 1 . The range of the tensile strength is from 2.16 to $3.87 \mathrm{MPa}$ and the corresponding facture strain is from 580 to $1040 \mu$. That is to say, the strain of $3000 \mu$ measured in the mold of a thickness of $3 \mathrm{~mm}$ in the thinly ground part is as high as three times the fracture strain of the mold. From the above experiments, it was observed that the mold without a thinly ground part has an even wall thickness of $10 \mathrm{~mm}$ and the strains distribute evenly in the circumferential direction thus the crack will occur if the stress corresponding to the strain in the mold exceeds the tensile strength. For the experimental mold, a filling irregularity of the sand during mold prepara-

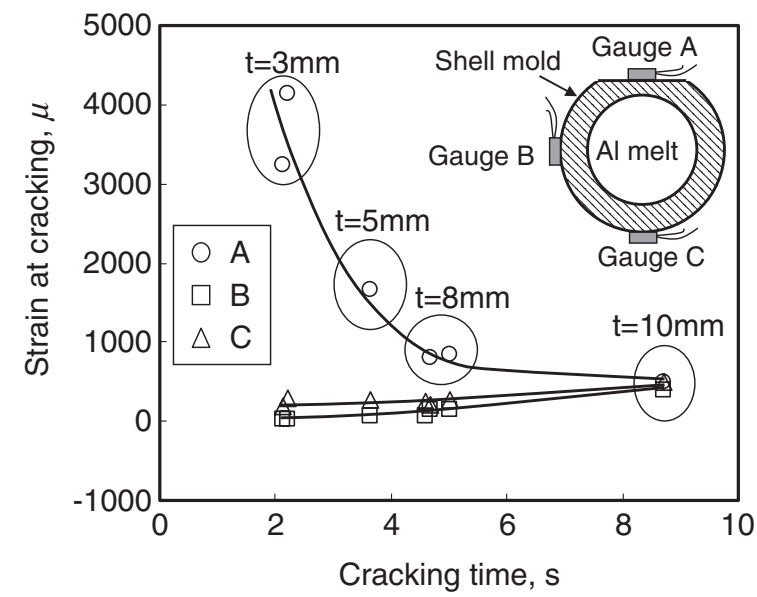

Fig. 8 Measured strains of the cylindrical shell molds with different thickness of thinly ground part at the time of crack occurring in the outer surface of the thinly ground part $60 \mathrm{~mm}$ high from the bottom.

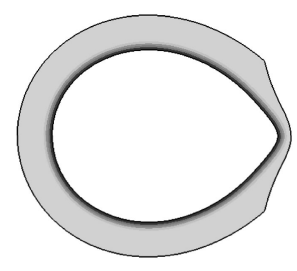

(a) Thickness $=3 \mathrm{~mm}$ $t=2 s$

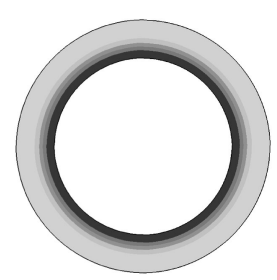

(b) Thickness $=10 \mathrm{~mm}$ $\mathrm{t}=10 \mathrm{~s}$
Fig. 9 Cross section shapes of shell molds with different thickness of thinly ground part after melt filling (100 times amplified) (two dimension analysis).

tion can be considered and the crack will occur at the weakest point of the mold. In the case that a part of the mold wall is thinly ground, a comparatively large strain generated in the thinly ground part. The strain increased rapidly and a crack occurred during melt filling with the decrease of the thickness of the thinly ground part. However, the reason why the strain at cracking increased with the decrease of the thickness of the thinly ground part is left to be explained.

The temperature distributions in and the deformation configurations of the cross sections of the cup-shaped molds with and without a part of the mold wall thinly ground at cracking are illustrated in Fig. 9. For the mold without thinly ground part (an even wall thickness of $10 \mathrm{~mm}$ ), the cross section remained a circular shape although enlarged. While for the mold with a part thinly ground from 10 to $3 \mathrm{~mm}$, the thinly ground part deformed significantly from the initial circular shape to the shape of a larger curvature and the curvature increased with the decrease of the thicknesses of the thinly ground part, especially when the thickness of the thinly ground part was less than $5 \mathrm{~mm}$, the increase of the curvature became more marked. Owing to the thinner thickness, the thinly ground part has a bending moment thus a stress gradient in the thickness direction during melt filling. The stress gradient became larger with the decrease of the thickness of the thinly ground part. It can be explained that it was just the stress gradient that made the fracture stress 
(strain) of the mold much higher than the tensile strength as it is generally observed that the bending strength is higher than the tensile strength with the same size of specimens for a brittle material.

\subsection{Criterion for mold cracking}

For a mold that is exposed to an even distribution of tensile stress, for example in the case of the cup-shaped mold without thinly ground part, the tensile strength of the mold can be considered as the criterion for mold cracking, i.e., if the tensile stress in the mold exceeds the tensile strength cracks will occur. However, as was observed in the above experiments, if there is a large bending moment or a severe gradient of stress in the section of a mold the cracking stress will increase thus the tensile strength obtained by tensile test can not be used as the criterion for cracking. Therefore the criterion for cracking under a severe stress gradient condition was examined by the effective volume method which is based on the Weibull's statistics and is utilized for evaluating the strength of brittle materials. The effective volume $\left(V_{\mathrm{E}}\right)$ is a parameter based on the assumption that the larger the volume bearing comparatively high stress in a body is, the larger the probability is containing comparatively larger defects which are able to become the origins of cracks. The effective volume is described by eq. (1).

$$
V_{\mathrm{E}}=\int_{\mathrm{V}}\left(\sigma / \sigma_{\max }\right)^{\mathrm{m}} \mathrm{d} V
$$

Where, $\sigma$ is the stress in the specimen, $\sigma_{\max }$ is the maximum stress in the specimen, $m$ is the Weibull's parameter, $V$ is the total volume of the specimen.

The relation between the mean fracture stress $\mu$ and the effective volume $V_{\mathrm{E}}$ of a brittle material can be expressed as:

$$
\ln \mu=-(1 / m) \cdot \ln V_{\mathrm{E}}+c
$$

Where, $c$ is a constant.

Further more, for a given fracture probability $F$ the fracture stress can be obtained from the above mean fracture stress by eq. (3).

$$
\sigma_{\mathrm{F}}=\mu / S_{\mathrm{p}}
$$

Where, $S_{\mathrm{p}}$ is safety coefficient and can be calculated by eq. (4).

$$
S_{\mathrm{p}}=\Gamma((m+1) / m) /(\ln (1 /(1-F)))^{1 / \mathrm{m}}
$$

Where, $\Gamma(x)$ is the Gamma function.

If the Weibull's parameter $m$ and the constant $c$ are known, the relation between the fracture stress for a given fracture probability and the effective volume can be obtained by putting eqs. (2) and (4) into eq. (3). The Weibull's parameter $m$ and the constant $c$ were calculated from the tensile test results as follows.

At first, the Weilbull plot of the tensile test results was drawn as shown in Fig. 10. Here, the median rank method was adopted for calculating the fracture probability because of the small tensile test number 10. The Weibull's parameter was calculated as 6.04 from the tangent of the Weibull plot in Fig. 10. This Weibull's parameter is in between 5 20 which is the typical range for general ceramics although it is at the side of a comparatively larger fluctuation.

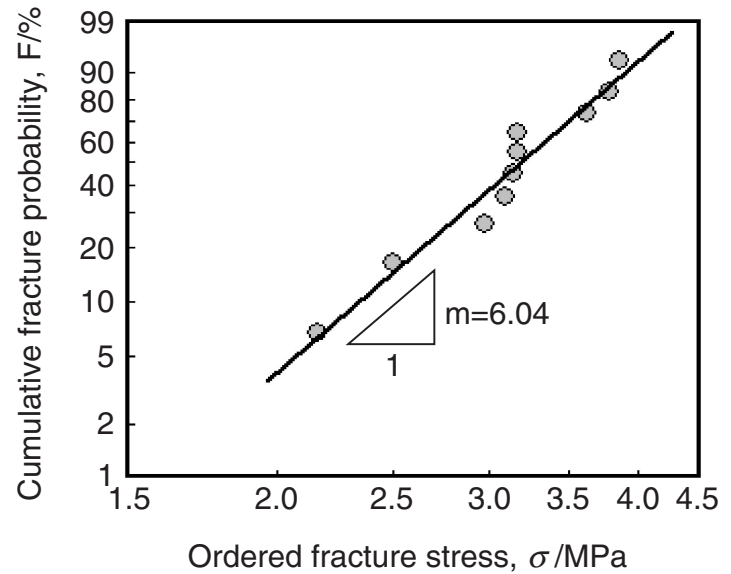

Fig. 10 Weibull plot of the fracture stresses obtained by tensile tests of the shell mold material.

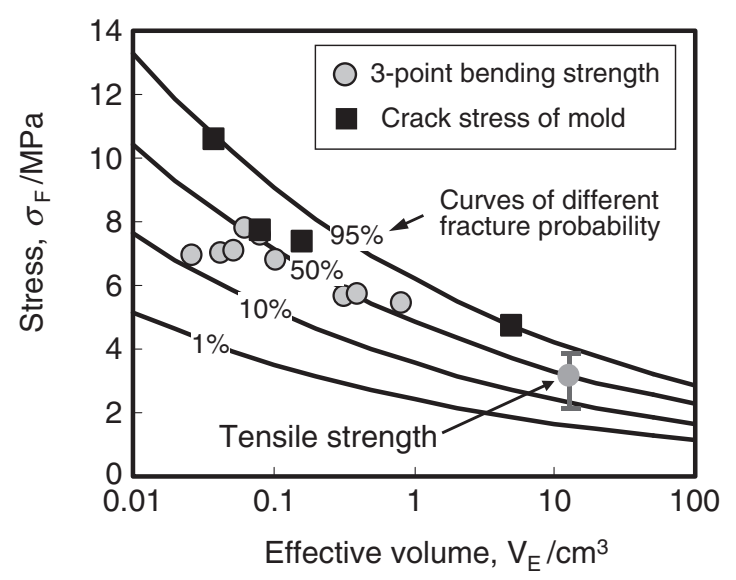

Fig. 11 Relationship between the fracture stress and the effective volume of the shell mold material.

If only the gage length region of the tensile specimen is taken into account when calculating the effective volume of the tensile test, the effective volume simply equals the volume of the gage length region of the specimen because the stresses everywhere in the gage length region are the same, i.e., $\sigma=\sigma_{\max }$ in eq. (1). However, in the practical tensile tests, some of the specimens did not fracture in the gage length region but in the transition region that just a little away from the gage length region of the specimen. Therefore, the integration range of eq. (1) was extended from the gage length region to the transition regions and the effective volume of the tensile specimen was calculated as $V_{\mathrm{E}}=$ $12.6 \mathrm{~cm}^{3}$. Here, it should be noted that the cross section of the transition region is larger than that of the gage length region thus the stress in the transition region is smaller than that of the gage length region.

By putting $m=6.04, V_{\mathrm{E}}=12.6 \mathrm{~cm}^{3}$ and the mean tensile strength $\mu=3.15 \mathrm{MPa}$ into eq. (2), the constant $c$ was obtained as $c=4.72$.

The relations between $\sigma_{\mathrm{F}}$ and $V_{\mathrm{E}}$ corresponding to the fracture probabilities of $F=1 \%, 10 \%, 50 \%$, and $95 \%$ were achieved by putting eq. (2) and eq. (4) into eq. (3). The relations of $\sigma_{\mathrm{F}}$ and $V_{\mathrm{E}}$ are illustrated in Fig. 11 and it is noticed that fracture stresses increase with the decrease of 

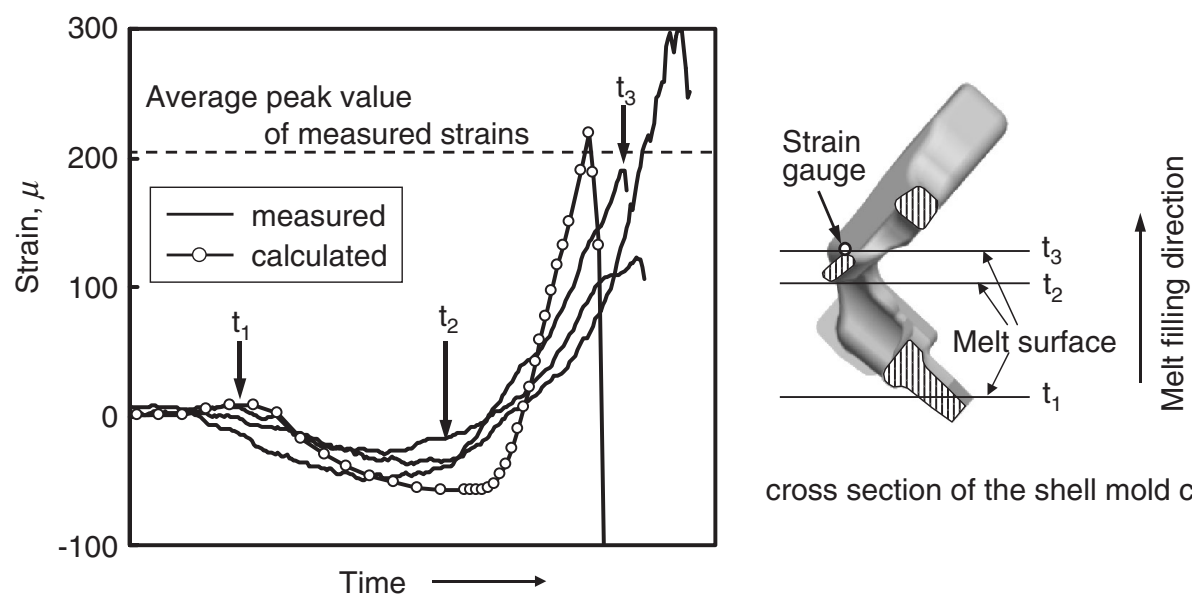

cross section of the shell mold core

Fig. 12 Comparison of the measured and calculated strains of the water jacket shell mold core of the cylinder head during melt filling.

effective volumes. The bending strengths measured by three points bending test with specimens of different effective volumes are also plotted in Fig. 11 (solid circles) and a good agreement can be confirmed with the calculated fracture stresses from the tensile test strengths.

The maximum principal stresses and the effective volumes at cracking were calculated for the cup-shaped molds of thinly ground part shown in Fig. 8. The result for each mold is plotted in Fig. 11 (solid squares). It can be found that the maximum principal stresses at mold cracking locate in the region of the fracture probabilities of $50 \sim 95 \%$, thus the region of fracture probabilities over $50 \%$ can be considered as the criterion for shell mold cracking.

\subsection{The cracking prediction of a jacket core for aluminum alloy cylinder heads}

To predict the occurrence of cracks correctly, it is necessary to know the detail process that molds contact melt during casting by melt filling simulation first and then calculate the thermal stress in the molds based on the heat transportation between molds and melt. The measured strains $(N=3)$ in the jacket mold were illustrated in Fig. 12 when the mold was heated as melt surface rose from the down side through the upper side of the cross section of the mold. Compressive strains were measured when the surface of melt rose from $t_{1}$ to $t_{2}$. The strains began to change towards the tensile side at the time the surface of melt passed $t_{2}$ and continuously increased with the rise of melt surface. When melt surface arrived at the position of the installed strain gages, the strains suddenly dropped to the compressive side and the strain gages were damaged due to contacting with the hot melt at last. The strain of the mold calculated based on the melt filling simulation by the foundry CAE software TOPCAST was also shown in Fig. 12. It can be noticed that the calculated strain shows almost the same tendency as the measured strains. The distribution of the maximum principal stress in the mold (the part of one cylinder) was shown in Fig. 13 when the surface of melt passed $t_{2}$ and just before arrived at the position of the strain gage in Fig. 12. The maximum value of the maximum principal stress is about $1 \mathrm{MPa}$ and much lower than the tensile strength of the mold, locating at the position of a fracture probability lower than

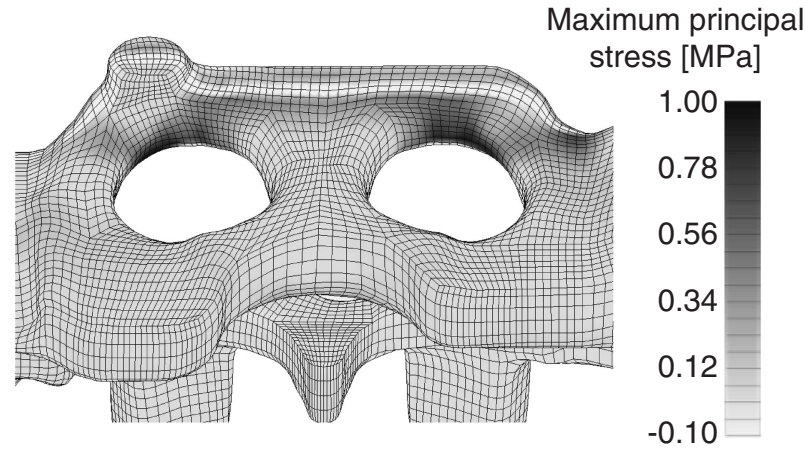

Fig. 13 Stress distribution in the water jacket shell mold core of a cylinder head during melt filling at $t_{3}$ in Fig. 12 .

$1 \%$ in Fig. 11. Therefore, the risk of cracking is extremely low under the present casting conditions.

\section{Conclusions}

The cracking phenomenon of shell molds during casting JIS-AC4C aluminum alloy was investigated focusing on the thermal stress in the mold arising from being heated by melt and the following conclusions were obtained.

(1) The temperature of the inner side of cup-shaped mold increases due to being heated by aluminum melt. The thermal expansion of the inner side corresponding to the temperature increase is restrained by the outer side of the mold that is still at low temperature resulting to compressive and tensile stresses in the inner and outer sides of the mold respectively. The tensile stress in the outer side of the mold can rise to a high level in a short time. If the tensile stress exceeds the tensile strength of the mold, crack will occur.

(2) Even if tensile stress occurs in the outer side of a mold, if the side is heated by melt before the stress exceeds the tensile strength, the tensile stress will decreased rapidly and no crack will occur.

(3) For a cup-shaped mold with thinly ground part, cracks occur in the thinly ground part and the cracking time decreases with the decrease of the thickness of the thinly ground part.

(4) In a mold with thinly ground part, the maximum tensile 
stress occurs in the thinly ground part and cracks occur in this part. The cracking stress increases with the decrease of the thickness of the thinly ground part.

(5) The cracking criterion for shell molds can be described by the effective volume method which is used for assessing the strength of brittle materials based on the Weibull's statistics, i.e., whether cracks occur or not can be judged by comparing the tensile stresses in the surfaces of molds with the fracture stress (strength) of the same effective volume in the fracture stress-effective volume relation graph which can be obtained by tensile or bending tests.

(6) The proposed cracking criterion in the present research was proved of reliability through applying to the cracking prediction of water jacket molds in the casting process of cylinder heads.

\section{Acknowledgements}

The authors are grateful to the people concerned in SANEI
SILICA Ltd. Japan for their help in the measurements of the properties of shell molds.

\section{REFERENCES}

1) J. Cmpbell: CASTINGS, (Butterworth-Heinemann Ltd., 1991) p. 98.

2) T. Makiguchi: IMONO 62 (1990) 566-573.

3) H. Oota, Y. Sakaguchi, K. Kuniyoshi and H. Murata: Report of JFS Meeting 152, (1979) p. 48.

4) R. E. Morey: Trans. AFS 54 (1949) 129.

5) S. Katashima, S. Tashima and Y. Mikawa: Report of AFS Meeting 113, (1988) p. 91.

6) T. Nakano, K. Muto and H. Tanabe: IMONO 50 (1978) 36.

7) M. Yajima and H. Hase: IMONO 55 (1983) 765.

8) I. Onaka: J. JFS 78 (2006) 602-608.

9) Y. Otsuka: J. JFS 78 (2006) 609-614.

10) The Ceramic Society of Japan: The Mechanical Properties of Ceramics, (1979) pp. 22-23.

11) R. W. Davidge: Translated by Hiroshige Suzuki, Takayoshi Iseki, The Strength and Fracture of Ceramics, (Kyoritsu Shuppann, 1982) p. 147. 